\title{
"O MUNDO TEM QUE SABER DISSO DE ALGUMA MANEIRA": CRÍTICA DAS PRÁTICAS JORNALÍSTICAS NA REFLEXÃO DE JORNALISTAS BRASILEIRAS ${ }^{1}$
}

\author{
"THE WORLD MUST KNOW ABOUT THAT IN SOME WAY": A CRITICISM \\ OF JOURNALISM PRACTICES IN THE REFLECTION OF BRAZILIAN \\ JOURNALISTS
}
"EL MUNDO NECESITA SABER DE ESO DE ALGUNA MANERA": CRÍTICA DE LAS PRÁCTICAS PERIODÍSTICAS EN LA REFLEXIÓN DE PERIODISTAS BRASILEÑAS

Angela Zamin

Professora do Departamento de Ciências da Comunicação, UFSM angelazamin@gmail.com

Taiz Gizele Richter Acadêmica de Jornalismo, UFSM taiz_richter@hotmail.coml

Tatiane Milani Acadêmica de Jornalismo, UFSM tati_milanis@hotmail.com

Tonie Maria Gregory dos Santos Acadêmica de Jornalismo, UFSM tonie.maria@hotmail.com

\section{Resumo}

O presente artigo analisa os livros Palestinos, os novos judeus (1977), de Helena Salem, e Viagem à Palestina: prisão a céu aberto (2013), de Adriana Mabilia, jornalistas brasileiras, a partir de uma reflexão que considera as características, a ambiência e as dificuldades próprias ao Jornalismo internacional. $O$ texto perpassa a crítica à cobertura internacional, especialmente de conflitos, trata da crítica trazida pelas fontes e chega à autocrítica esboçada pelas repórteres ao abordarem o próprio fazer, como resultado de uma atitude reflexiva sobre as práticas jornalísticas proposta no interior do próprio sistema. A partir dos conceitos de crítica (FOUCAULT, 2008; RÜDIGER, 2014) e de crítica das práticas jornalísticas (BERGER; MAROCCO, 2014), estuda sua elaboração por jornalistas em "livros de repórter" (MAROCCO, 2011; ZAMIN, 2011).

\footnotetext{
${ }^{1}$ Versão revista de trabalho apresentado no XVI Congresso de Ciências da Comunicação na Região Sul. Os resultados apresentados integram o projeto de pesquisa "Jornalismo e narrativa: percursos e procedimentos de duas repórteres brasileiras na Palestina".
} 
Palavras-chave: Crítica das práticas jornalísticas. Livros de repórter. Conflito IsraelPalestina.

\begin{abstract}
This article analyzes the books Palestinians, the new Jews (1977), by Helena Salem, and Journey to Palestine: open-air prison (2013), by Adriana Mabilia, who are both Brazilian journalists, from a reflection that considers the characteristics, the ambiance and the intrinsic difficulties to international Journalism. The text goes through the criticism of international coverage, especially those of conflicts, deals with the criticism brought by the sources and reaches the self-criticism outlined by the reporters when they address their own work, as the result of a reflexive attitude about the journalism practices proposed within the system itself. From the concepts of criticism (FOUCAULT, 2008; RÜDIGER, 2014) and of criticism of journalism practices (BERGER; MAROCCO, 2014), it studies their elaboration by journalists in "books written by reporters" (MAROCCO, 2011; ZAMIN, 2011).
\end{abstract}

Keywords: Criticism of journalism practices; Books written by reporters; Israel-Palestine conflict.

\title{
Resumen
}

Este artículo analiza los libros Palestinos, los nuevos judios (1977), de Helena Salem, y Viajen à Palestina: prisión a cielo abierto (2013), de Adriana Mabilia, periodistas brasileñas, desde una reflexión que considera características, atmósfera y dificultades propias del periodismo internacional. El texto transcurre a través de la crítica a la cobertura internacional, sobre todo de conflictos, se ocupa de la crítica presentada por las fuentes y alcanza a la autocrítica esbozada por las periodistas al enfocar el propio hacer, como resultado de una actitud reflexiva sobre las prácticas periodísticas propuesta dentro del propio sistema. A partir de los conceptos de crítica (FOUCAULT, 2008; RÜDIGER, 2014) y de crítica de las prácticas periodísticas (BERGER; MAROCCO, 2014), estudia su elaboración por periodistas en "libros de reportero" (MAROCCO, 2011; ZAMIN, 2011).

Palabras clave: Crítica de las Prácticas Periodísticas; Libros de Reportero; Conflicto IsraelPalestina.

Esta obra está licenciada sob uma Licença Creative Commons

\section{INTRODUÇÃO}

Este texto é resultado das primeiras reflexões acerca da crítica das práticas jornalísticas elaborada por jornalistas. Para tanto, toma como locus de observação e análise "livros de repórter" (MAROCCO, 2011; ZAMIN, 2011). Inserido em uma pesquisa mais ampla, gestada no interior do Resto - Laboratório de Práticas Jornalísticas (CNPq/UFSM), voltada aos temas do contemporâneo, o artigo propõe-se a analisar os livros Palestina, os 
novos judeus (1977), de Helena Salem, e Viagem à Palestina: prisão a céu aberto (2013), de Adriana Mabilia, jornalistas brasileiras, a partir de uma reflexão que leva em conta as características, a ambiência e as dificuldades próprias ao Jornalismo internacional. A leitura destes livros não seguiu uma ordem cronológica; o de Mabilia nos levou ao de Salem. Entre eles, Oriente próximo (2007), da portuguesa Alexandra Lucas Coelho, e Palestina (2011), do maltês Joe Sacco, também foram objetos de estudo, mas que aqui não serão acionados.

O artigo analisa a crítica à cobertura internacional, especialmente de conflitos, trata da crítica trazida pelas fontes e chega à autocrítica realizada pelas repórteres ao abordarem seu próprio fazer, como resultado de uma atitude reflexiva sobre as práticas jornalísticas proposta no interior do sistema jornalístico. ${ }^{2}$ Tal entendimento deve-se ao fato de compreendermos o "livro de repórter" como espaço de reflexão sobre as práticas, de formulação da experiência, de elaboração da crítica e de deslocamento do Jornalismo ao Jornalismo. Nestes livros, ao se ocupar do fazer jornalístico para, a partir dele, elaborar outro relato, o repórter pode produzir uma exegese do saber jornalístico.

A carioca Helena Salem (1948-1999), judia de sobrenome árabe, filha de imigrantes turcos, concluiu a Graduação em Ciências Sociais na Universidade Federal do Rio de Janeiro em 1970. Durante a faculdade, em 1968, começou a trabalhar no Jornal do Brasil (JB), como redatora de Internacional, e se especializou em Oriente Médio. Passou um ano na Itália, em Florença, cursando uma Pós-Graduação em Política Internacional e, ao seu término, foi para o Oriente Médio conhecer de perto a realidade dos países que estudava e sobre os quais escrevia. Ao chegar ao Egito, em 1973, deparou-se com a guerra entre países árabes e Israel, conhecida como Guerra do Yom Kippur no Ocidente e do Ramadã entre os árabes, e cobriu-a para o JB. Palestina, os novos judeus (1977), aqui analisado, e Entre árabes e judeus: uma reportagem de vida (1991), livro autobiográfico, tratam da cobertura do conflito e, especialmente, dos palestinos.

Pouco tempo após retornar do Oriente Médio Salem exilou-se em Portugal devido à perseguição da ditadura militar brasileira, atuando como correspondente da IstoÉ e do Jornal Movimento e contribuindo para o jornal português O Expresso. Em 1979 voltou ao Brasil. Tornou-se repórter e articulista free lancer em jornais como O Globo, Jornal do Brasil, Folha de S. Paulo e O Estado de S. Paulo, neste último trabalhando até sua morte. Dedicou-se à

\footnotetext{
${ }^{2}$ Divididos em grupos, docentes e discentes do Resto - Laboratório de Práticas Jornalísticas dedicaram-se a analisar questões importantes ao Jornalismo, como: (1) procedimentos e rotinas; (2) crítica das práticas jornalísticas e (3) experiência. O movimento de pesquisa originou três artigos que, partindo dos mesmos livros, seguem em direções variadas, porém complementares.
} 
cobertura de cinema e realizou com Jorge Bodanzky o documentário Igreja dos Oprimidos. Segundo a Folha de S. Paulo, Helena foi a primeira correspondente de guerra brasileira. ${ }^{3}$

Adriana Mabilia (1969) é especialista em Oriente Médio pela Pontifícia Universidade Católica de São Paulo. Jornalista, trabalhou no telejornalismo e em revistas. Foi editora na $T V$ Cultura e na Rede Record e, atualmente, é editora de Internacional do Jornal Hoje, da TV Globo. Viagem à Palestina, todavia, não resulta da reescrita de reportagens, mas de um interesse pessoal em ouvir as palestinas, fontes silenciadas na cobertura do conflito. "A dificuldade de encontrar informações sobre a população feminina palestina fez brotar a ideia do livro e dessa viagem", afirma Mabilia (2013, p. 40), que foi para a Palestina quatro vezes. ${ }^{4}$ Durante a pesquisa para o livro, contudo, acabou produzindo reportagens factuais para a revista brasileira Caros Amigos. ${ }^{5}$

\section{SOBRE O JORNALISMO INTERNACIONAL}

[...] nem tudo o que é notícia aparece no noticiário internacional. O noticiário não constrói um retrato do mundo com determinado grau de exatidão, muita coisa que será vista no futuro como de capital importância histórica é diariamente deixada de lado. E, ao mesmo tempo, certos temas sem importância histórica nenhuma acabam virando notícia. (NATALI, 2007, p. 12).

O Jornalismo internacional tem a característica de informar-nos daquilo que acontece no mundo. Segundo Espinosa de Los Monteros (1998, p. 416), o Jornalismo internacional é um "fenômeno da atividade intelectual e econômica" que data da segunda metade do século 19, cuja trajetória está "ligada ao desenvolvimento da escrita, à imprensa, à indústria editorial, às tecnologias de comunicação e ao transporte". Para o autor, o Jornalismo impresso, que data do século 16, tomou forma a partir de algumas condições de desenvolvimento da economia de mercado, que posteriormente aos avanços tecnológicos de impressão e produção em massa de papel, originaram a mudança da imprensa política e literária do século 19 para o Jornalismo diário. As notícias do exterior entraram tardiamente nas páginas dos jornais.

Na visão deste autor, a matéria-prima do Jornalismo internacional foi a economia:

O jornalismo é uma atividade econômica do capitalismo, que em suas origens satisfez a necessidade de comunicação dos comerciantes e

\footnotetext{
${ }^{3}$ Morre no Rio a jornalista Helena Salem. Folha de S. Paulo, Mortes, São Paulo, ano 79, n. 25.712, 26 ago. 1999. Disponível em: <http://acervo.folha.com.br/fsp/1999/08/26/264//663185>.

${ }^{4}$ Dados da entrevista concedida pela jornalista Adriana Mabilia, em novembro de 2014, por e-mail.

${ }^{5}$ Trata-se da edição Especial Oriente Médio, de Caros Amigos, que circulou em maio de 2009.
} 
banqueiros, de informar-se sobre os preços de mercadorias e mercados de grãos e metais. (ESPINOSA DE LOS MONTEROS, 1998, p. 418).

Natali (2007, p. 22), todavia, argumenta que o Jornalismo já "nasceu internacional" com os primeiros órgãos jornalísticos da modernidade, os newsletters, que eram "boletins noticiosos mercantis da burguesia neerlandesa em comércio com outras nações no século XVII". Foi nesse período, de acordo com o autor, que passaram a circular os primeiros jornais impressos com ênfase nas informações e fatos ocorridos no exterior.

Poderíamos supor que o jornalismo surgiu como atividade que fizesse circular informações de interesse local ou paroquial, já que o campo de interesse comum dos mortais, em comunidades compartimentadas, sofria os efeitos de uma infra-estrutura precária de comunicações. Pois suporíamos errado. $\mathrm{O}$ jornalismo nasceu, isto sim, sob a forma de jornalismo internacional, com o formato de coleta de difusão de notícias produzidas em terras distantes. (NATALI, 2007, p. 23).

O surgimento e o desenvolvimento das pioneiras agências de notícias internacionais, a partir da segunda metade do século 19, estiveram vinculados à expansão do capitalismo, quando "as notícias sobre o exterior ganham seu espaço na imprensa diária" (ESPINOSA DE LOS MONTEROS, 1998, p. 416). Inicialmente, também para as agências, a informação econômica, além dos conflitos armados, era a matéria-prima (SILVA, 2011). Segundo Zamin (2012, p. 50), "as primeiras agências atuavam como monopólios delimitados sobre o traçado das fronteiras nacionais".

Atualmente as agências mais importantes, que impõem o rumo das notícias internacionais, são a francesa Agence France Presse (AFP), as estadunidenses United Press International (UPI) e Associated Press (AP), a inglesa Reuters, a italiana Agenzia Nazionale Stampa Associata (ANSA) e a alemã Deutsche Presse-Agentur (DPA), às quais se soma a espanhola EFE. Há outras, menores, no entanto, muitas vezes de cobertura regional.

As agências de notícia constituem uma parte importante da rede informativa, especialmente porque, simbolicamente, estão em todos os lugares ao mesmo tempo. Por meio das agências as empresas jornalísticas podem acessar o que ocorreu em uma localidade desconhecida num país distante qualquer, ou no país que está ao seu lado, com o qual compartilham fronteiras comuns e fluxos de toda ordem. (ZAMIN, 2012, p. 49).

A rede das grandes agências é abrangente. Elas estão presentes e/ou vendem seus serviços para parte significativa do mundo. Segundo Peres (2005), em artigo para o Observatório de Imprensa, o Jornalismo internacional está vinculado à produção de notícias, e esta, por sua vez, está ligada aos despachos de agências internacionais americanas e 
europeias, especialmente, que têm seus escritórios espalhados pelo mundo. Para esta autora, ainda que os despachos enviados sejam permeados pelos pontos de vista, posicionamentos e ênfases de quem os envia, cabe aos editores que os recebem personalizá-los para que fiquem dentro das normas editoriais de cada meio.

Há, portanto, um esforço do redator ou editor no Brasil em personalizar o noticiário internacional de seu jornal, o que influi na redação/edição das notícias e fotografias desses despachos e que acrescenta opiniões e posicionamentos críticos, artigos de seus correspondentes internacionais, (mais raramente) de seus enviados especiais e pesquisas realizadas na própria redação do jornal. (PERES, 2005).

A autora comenta, ainda, que as notícias são oriundas, na maioria das vezes, de um Jornalismo "feito fora do Brasil, por jornalistas não brasileiros" (2005). Dessa forma, o noticiário internacional é dependente de um Jornalismo conformado a partir dos lugares e dos acontecimentos mapeados pelas agências. Além delas, o Jornalismo internacional resulta do trabalho de correspondentes, stringers, free lancers e de repórteres sediados nas redações no país, por vezes deslocados para o exterior na condição de enviados especiais. O jornalista brasileiro Carlos Eduardo Lins da Silva (2011, p. 15) parte do entendimento de que o correspondente internacional é

[...] o jornalista sediado em um país que não o seu de origem com a missão remunerada de reportar fatos e características dessa sociedade em que vive para uma audiência da sua nação materna por meio de um veículo de comunicação.

O espanhol Héctor Borrat concorda com essa definição:

A figura do correspondente identifica um tipo de jornalista profissional que se apresenta em agências de notícias, jornais, revistas e emissoras de rádio e de televisão; trabalha para qualquer uma destas organizações, de maneira permanente, fora da sede central de sua redação, seja dentro ou fora do país. Envia informações, comenta acontecimentos e representa sua redação perante organizações de todo tipo. Pode pertencer ao quadro funcional de sua empresa ou atuar como um simples colaborador que cobra por trabalho. [...] o correspondente é o típico habitante da diáspora jornalística, destinado a trabalhar em um dos lugares em que o jornal concentra seus esforços informativos. (BORRAT, 1989, p. 63).

O correspondente precisa explicar os acontecimentos para um público que deles não participa. "Ele tem de traduzir a realidade do país em que está, e fazer o máximo possível de comparações que permitam às pessoas identificar o que está acontecendo com os referenciais que estão acostumadas a usar aqui” (UTZERI, 1989, p. 56). Já o enviado especial, embora 
desempenhe as mesmas funções do correspondente, "viaja por períodos curtos com a missão de cobrir um evento específico" (SILVA, 2011, p. 15). São enviados especificamente para a cobertura de um acontecimento. O free lancer trabalha informalmente, vendendo reportagens avulsas, ou temporariamente, cumprindo uma pauta específica. Já o stringer é uma espécie de free lancer fixo, acionado sempre que um meio necessita de uma reportagem do lugar em que este se encontra sediado.

\section{A CRÍTICA À COBERTURA INTERNACIONAL EM LIVROS DE REPÓRTER}

[...] ao longo dos poucos mais de dez anos que estudo o tema e acompanho o conflito, há uma questão com a qual eu sempre me deparo; aliás, questão essa que serve para tudo: os fatos. Não há como negar fatos. Por mais que os poderosos tenham mais acesso à mídia, à propaganda, e com isso tenham instrumentos para manipular e distorcer informações, o que aconteceu ninguém muda e a verdade aparece. $\mathrm{E}$, por mais que essa verdade pareça ter perdido a importância e o valor entre os homens que mandam no mundo, alguém tem que zelar por ela, porque, se não, o que será de nós? (MABILIA, 2013, p. 202).

Os livros escritos por repórteres podem constituir-se em espaço para a visibilidade e a crítica das práticas jornalísticas. Para tanto é fundamental que os profissionais, ainda que afetados por normas que balizam as rotinas produtivas, concebam um modo de se relacionar com o ocorrido enquanto alguém que se agarra àquilo que está se passando. Foucault (2008), por meio do que chamou de "reportagens de ideias", sugere que o Jornalismo se desloque de seu lugar hegemônico para abarcar o presente por outra lógica, propõe uma modificação na concepção de fonte jornalística e no trabalho a ela dispensado e oferece a "leitura" do intelectual sobre o presente que ora testemunha. A interrogação de Foucault: "O que está acontecendo com nosso presente, que não chega até nós" (MAROCCO, 2008, p. 44), tomada como ferramenta de crítica das práticas, permite analisar os livros de repórter enquanto espaço de discussão do Jornalismo e dos temas do contemporâneo que nele ingressam.

O Jornalismo internacional enfrenta certas dificuldades, a exemplo das que envolvem a distância física em relação ao objeto da notícia. Para supri-las, muitas vezes, os meios se apropriam do conteúdo de outros, que lhes servem de fonte, os meios-fonte (BORRAT, 1989), revelando ou não a procedência no interior do texto jornalístico. A "apropriação" é orientada pela necessidade de se informar conjugada a um alinhamento editorial, ou seja, de antemão há uma identificação com o jornal que lhe serve de fonte. 
Como forma de facilitar este processo, jornais de referência ${ }^{6}$ e agências possuem vários tipos de "produtos" à disposição dos clientes (jornais, sites, etc.), como reportagens especiais (normalmente assinadas por repórteres mais experientes, correspondentes, entre outros) e textos de colunistas. Além disso, textos avulsos de determinado jornal podem ser adquiridos por outro para publicação. Algumas indicações no texto jornalístico, contudo, não permitem identificar a procedência da informação, como quando se substitui o nome de um jornal pela sua origem geográfica (Folha de S. Paulo por "um jornal brasileiro", Komsomolskaya Pravda por "um jornal russo").

Ao trabalhar com "apuração à distância", o Jornalismo internacional apresenta uma tendência "natural" à pré-mediatizar o trabalho jornalístico (via apuração por outras mídias); realizando uma permanente polifonia e reproduzindo discursos sobre discursos de outrem. Nesse processo, corre permanentemente o risco de negligenciar contextos, deslocar declarações e perenizar visões pré-concebidas. (AGUIAR, 2008, p. 19).

Adriana Mabilia, em Viagem à Palestina, faz uma crítica pontual a essas práticas ao afirmar: "E, dessa vez, eu não soube disso por meio de agências de notícias internacionais ou por relatos de outros jornalistas; estou vendo. Ninguém me contou, eu estou vendo" (2013, p. 92). As fontes entrevistadas pela jornalista reforçam a importância da presença do repórter no local dos acontecimentos, como a italiana Rosella, observadora de uma ONG, que afirma: "a Europa não tem ideia do que acontece aqui [...]. O povo palestino é um povo ocupado há décadas. Vive numa prisão a céu aberto [...]. E estou aqui há dois meses. O que Israel faz aqui é crime. O mundo tem que saber disso de alguma maneira" (p. 110).

Salem, em Palestina, os novos judeus, relata o emprego de procedimentos de apuração, anteriormente listados, trazendo para o texto jornalistas e jornais como fontes de informação. Faz uso deste expediente, todavia, como forma de contrapor as clássicas versões difundidas pela mídia. Em um desses usos, ao recuperar a pesquisa de um jornalista inglês, afirma que a investigação "pôs por terra o argumento também sionista de que os países árabes incitaram os palestinos a fugirem" (SALEM, 1977, p. 28). Vai além, alertando que o jornalista ouviu "todas as fitas gravadas das emissoras árabes durante a guerra de 1948, conservadas no Britsh Museum de Londres” (p. 28), mostrando-nos o Jornalismo como fonte em si mesmo, capaz de contribuir para pôr acontecimentos em relevo.

Outro problema a ser enfrentado é o escasso investimento das empresas jornalísticas em correspondentes, devido ao alto custo desta operação. Dito de outro modo, outra

\footnotetext{
${ }^{6}$ Ver Zamin (2014).
} 
dificuldade encontrada na produção do noticiário internacional é determinada pelo fator econômico, visto que jornais de grande e médio porte não têm condições de manter uma estrutura significativa de repórteres expatriados e optam por reproduzir conteúdo de agências nacionais e transnacionais e de jornais de referência.

À dispersão de repórteres por determinadas zonas, como parte da rede informativa conformada a partir da ordem institucional de cada meio, somam-se as ordens de produção e discursiva. Juntas, definem editorialmente cada meio de comunicação e a forma como os acontecimentos do mundo serão enquadrados (ZAMIN, 2012). As críticas tecidas por Mabilia e Salem perpassam o posicionamento dos veículos, enquanto resultado da política editorial e das rotinas produtivas.

A maneira como a maior parte da imprensa mundial trata esses ataques é normalmente, no mínimo, irresponsável, pois contribui para que a ocupação dos territórios palestinos pelos israelenses continue sem solução. E eu não me eximo de culpa, apesar de que sempre tento explicar, mas o editor-chefe vai lá e corta. (MABILIA, 2013, p. 128).

Salem (1977, p. 92) corrobora esta leitura ao argumentar:

A imprensa ocidental apressa-se em demonstrar indignação com os atos terroristas palestinos, mas não se preocupa em informar sobre as condições que propiciam essa violência. Não publica com o mesmo destaque o sofrimento cotidiano, a morte cotidiana de milhares de refugiados, nem a repressão que sofrem nos territórios ocupados por Israel.

A crítica pode ser endereçada, ainda, aos editores e chefes de redação. Segundo Salem (1977, p. 10), o jornalista Alberto Dines, que respondia pela direção jornalística do JB, “embora sem esconder sua posição francamente pró-israelense, era aberto e consciente o bastante para prestigiar o trabalho de um bom profissional e querer oferecer ao leitor os vários aspectos de uma realidade". Quando de seu retorno ao Brasil, no entanto, e diante da mudança na direção, afirma que o jornal "vivia um período de muita indefinição e preferiu, por algum tempo, manter-me em silêncio" (p. 10).

A crítica de Mabilia (2013) estende-se para os processos de edição jornalística, sobretudo para o pouco espaço na página impressa e no telejornalismo. Diante disso, aspectos significativos para a cobertura internacional ficam comprometidos, como as questões de contexto e o contraste de pontos de vista.

A informação tem que caber em 30 segundos, e, por mais que o jornalista domine a técnica da síntese, palavra curta tem limite.

Com raras exceções, e raríssimos editores-chefes, em geral o que vai para a lixeira é o que dá contexto ao factual. O telespectador só fica sabendo que 
uma mulher-bomba explodiu e matou. O comentário é: nossa, que povo louco, são terroristas, gente violenta.

A imprensa escrita também não é diferente. (2013, p. 128).

A reduzida presença de repórteres estrangeiros em zonas de conflito não pode ser atribuída, de modo apressado, apenas a fatores econômicos e/ou às escolhas editoriais e/ou à comodidade dos despachos das agências internacionais. O perigo a que o jornalista será exposto é elemento decisivo neste processo, interferindo no momento de enviá-lo para cobrir os acontecimentos. Nestes casos, a cobertura internacional pode ser atribuída a sujeitos que vivem nos locais do conflito. É o exemplo que nos traz Mabilia (2013, p. 48), ao entrevistar Suheir, mulher palestina, que afirma que "jornais e revistas não mandavam seus jornalistas para cá, pois era muito arriscado. Então, alguns de nós, palestinos, fazíamos o papel da imprensa".

\section{AS FONTES E A CRÍTICA À COBERTURA SOBRE A PALESTINA}

Acho que tanto a imprensa brasileira como a estrangeira, quando falam do conflito, deixam de mostrar os dois lados. Por exemplo, no caso da mulherbomba que se explodiu em 4 de outubro de 2003. [...], o fato que levou essa mulher a cometer esse atentado foi a morte de seu esposo por soldados israelenses. Os jornais não disseram isso. Então, falta dar esse enfoque, pois para ela ter feito isso foi por algum motivo muito grave. (SAMHAN, in MABILIA, 2013, p. 64).

Mabilia (2013) e Salem (1977), nos livros analisados, nos mostram outro nível de crítica das práticas, a que chega pelas fontes. Isso porque ao modificarem a concepção e o tratamento a elas dispensado, conforme proposição foucaultiana anteriormente apresentada, as repórteres ofereceram às palestinas e aos palestinos a oportunidade de falar de si, do conflito Israel-Palestina e de como o Jornalismo os vê. Segundo Berger e Marocco (2014, p. 200), para a Teoria do Jornalismo, fonte é quem o "jornalista observa e/ou entrevista", reconhecido como tal por três atributos, "autoridade, produtividade e credibilidade"; 7 enquanto para a crítica das práticas jornalísticas, "a fonte não corresponde à autoridade, não têm o ônus da prova, nem da verdade, tampouco terá uma forma jornalística prescrita nos livros de estilo".

Se "a crítica pode ser definida como uma atitude diante do mundo" (RÜDIGER, 2014, p. 122), ela está presente tanto na reflexão das jornalistas quanto na dos palestinos ouvidos por elas. O movimento de fazer mulheres e homens palestinos ascenderem à categoria de fonte constitui-se em crítica ao Jornalismo hegemônico, as suas rotinas e aos modos como

\footnotetext{
${ }^{7}$ Sobre fontes jornalísticas ver: Santos (1997); Hall et al. (1999) e Lage (2009).
} 
este apreende as questões do tempo presente. Também o modo como os entrevistados veem o Jornalismo, mesmo que estimulados para tal, se estabelece como crítica. Entende-se, todavia, que o Jornalismo é perpassado por "jogos de interesses mesclados” e a fonte é parte da “jogada” porque está implicada, por uma parte, e porque insinua posições e interesses, por outra.

Nos livros das repórteres Adriana Mabilia e Helena Salem o contemporâneo é abarcado por lógicas outras, visto que nele ingressam sujeitos que se sentem prejudicados por, sucessivamente, não serem ouvidos e, também, objeções por não poderem expressar à imprensa aquilo que enfrentam todos os dias, as dificuldades, a situação em que se encontram. Em Viagem à Palestina, a crítica à cobertura internacional chega pelas vozes de mulheres palestinas ou descentes de palestinos, entrevistadas por Mabilia (2013) no Brasil, antes de viajar à região. Ahlan Nader Samhan, filha de palestinos, anteriormente citada, é uma delas.

Riam Dais, brasileira filha de palestinos, compartilha da mesma opinião de Ahlan. Em seu entendimento, “a imprensa brasileira não informa os dois lados. Quando Israel ataca, a justificativa é que foi resposta à violência dos palestinos. Quando um palestino ataca, não há justificativa, é como se ele tivesse atacado porque é selvagem, terrorista" (DAIS, in MABILIA, 2013, p. 60). Por sua vez, a advogada Jamile Abdel Latif, filha e mulher de palestinos, amplia a crítica:

\begin{abstract}
A sensação de revolta e impotência dos palestinos é imensa. Os judeus têm a mídia, a ONU, o Banco Mundial, o FMI, o dinheiro do mundo e repetem à exaustão que somos os bandidos. As pessoas parecem não estar interessadas em perguntar como começou o conflito: judeus e ameríndios invadiram nosso país e não quiseram conviver conosco porque se acham superiores. Sempre que acontece um ataque palestino, falta a imprensa dizer que o ataque é uma reposta natural palestina aos crimes cometidos por Israel na ocupação contra a Palestina. (LATIF, in MABILIA, 2013, p. 62-63).
\end{abstract}

A aproximação de Helena Salem é saudada pelos palestinos, quer em campos para refugiados, quer em bases guerrilheiras, embora marcada pela dificuldade em acessá-los porque "há muita desconfiança" dos jornalistas ocidentais (1977, p. 81). Em uma destas bases, no Líbano, o fedayin Nur El-Din afirma: "queremos saudá-la [...] por sua iniciativa de querer conhecer de perto a nossa realidade, e transmiti-la ao seu povo. Esperamos poder contribuir para sua compreensão do problema palestino, das razões de nossa luta, e de como lutamos" (p. 82).

Também no Líbano, em um campo de refugiados, o senhor Skander, ao ser entrevistado faz-lhe um pedido - "Por favor, diga a seu povo tudo que você viu. Os judeus, os 
americanos não são nossos inimigos. Os inimigos são o sionismo e o imperialismo, os palestinos lutam contra o sionismo e o imperialismo, lutam por seus direitos" (SALEM, 1977, p. 47) - e um agradecimento - "Obrigado por contar ao seu povo sobre a gente” (p. 47).

Mabilia deu preferência às fontes femininas com o objetivo de conhecer a realidade que as palestinas enfrentam. Suheir, diretora da TAM - Women \& Media Development, organização voltada às mulheres, observa que os problemas enfrentados por elas são os mesmos de outros lugares, e complementa: "a diferença é que, além de todos os encargos atribuídos à mulher, aqui na Palestina sofremos os danos de ser um povo sob ocupação" (2013, p. 49).

A crítica oriunda das fontes consultadas pode ter diversos destinatários, como a cobertura específica de um jornal, emissora de televisão ou rádio. Pode, ainda, ser endereçada diretamente ao jornalista ou ao Jornalismo como um todo. Nos livros analisados, entretanto, repetem-se os mesmos argumentos, quais sejam: que o mundo precisa saber do problema palestino e que a fonte mais capacitada para explicar sobre ele são os próprios palestinos.

\section{A CRÍTICA COMO REFLEXÃO SOBRE A PRÓPRIA PRÁTICA}

Eu agradeço a disponibilidade e explico que a entrevista é para uma importante revista brasileira [Caros Amigos] que publicará uma edição especial sobre a Palestina [...].

- Como o doutor avalia o que aconteceu na Faixa de Gaza?

- O que aconteceu em Gaza é um crime de guerra [...].

Eu interrompo e questiono: Mas Israel afirma que o alvo era o Hamas. Não é que eu acredite de fato na justificativa do governo israelense, mas é obrigação do repórter confrontar os dois lados. (MABILIA, 2013, p. 146, acréscimo nosso).

Contrastar os lados de uma história ou de uma realidade é dever de todo jornalista, pois faz parte da ética do profissional de Jornalismo. Ao analisar os livros de Adriana Mabilia e Helena Salem percebe-se a busca incessante em identificar, ouvir e contar as versões de um mesmo acontecimento, como no excerto da entrevista com o político e médico Mustafá Barghouthi, fundador do partido laico Al-Mubadara (Iniciativa Nacional Palestina), anteriormente citado.

À preocupação em mostrar as interpretações possíveis, soma-se a escolha de um lado. Nos livros, afirmam que ouvir todas as versões é um exercício necessário ao Jornalismo, contudo registram a opção pelo outro lado da história, aquele que muitas vezes é esquecido na cobertura internacional, o dos palestinos e das palestinas. Salem (1977) revela que o contato 
com refugiados palestinos em Beirute, então capital ocidental do mundo árabe, levou a esta decisão. "Foi então que me surgiu, pela primeira vez, a ideia de fazer um livro sobre os palestinos" (p. 10), revela. Mabilia (2013), como já referido, havia optado previamente por ouvir as mulheres palestinas.

O tempo que os repórteres passam nos lugares observando e, inclusive, vivenciando os acontecimentos, auxilia no entendimento do contexto e é responsável por uma compreensão e reflexão mais aprofundada da realidade. Essa vivência faz com que o repórter tenha suas próprias concepções e possa retratar a visão de quem vê "de dentro" o que está acontecendo e mostrar que, muitas vezes, a visão "de fora" pode estar distorcida. Ao refletir sobre o estar “dentro", relatar desde este lugar, Mabilia (2013) elabora uma autocrítica:

Entregar-me a essas sensações às vezes me causa culpa, pois o jornalista tem de manter o mínimo de distância dos acontecimentos para relatá-los de maneira imparcial e precisa. Tenho pleno conhecimento dessa regra e concordo com ela, mas, ao mesmo tempo, penso que estou aqui justamente para entender o que é viver num território ocupado. Então, viver essa experiência pela metade e bloquear os meus sentimentos, talvez, de alguma forma, também signifique ignorar e dar as costas aos fatos. (p. 93).

Em alguns trechos do livro Mabilia (2013) faz uma escrita de si, em que o medo, a tensão e o constrangimento são elementos importantes à reflexão sobre o próprio fazer. Percebe que muitas vezes acaba tocando em questões delicadas para os entrevistados e faz disso um exercício de autocrítica: "constrangida estou eu" (p. 47); "isso tem sido um tanto quanto constrangedor para mim" (p. 166); "é obvio que minha pergunta foi mal elaborada" (p. 47); "estou levando essas pessoas a mexer em feridas ainda abertas e isso dói” (p. 166), e “jornalista, normalmente, traz problema, porque transforma o que vê em notícia” (p. 169). Em outros, mostra-se insegura diante das situações que vivencia junto com os palestinos que observa e entrevista:

É um momento de tensão. Os soldados, então, jogam a cerca de arame farpado em cima de nós para nos afastar. Eu corro, com medo, as crianças também, mas o resto do pessoal não arreda pé, então eu volto. Alguns rapazes estão com as mãos sangrando. Machucaram-se na cerca. Mas eles continuam. (MABILIA, 2013, p. 85).

Questões de gênero também marcam a reflexão sobre a própria prática jornalística. Mabilia (2013, p. 17-18) sabe que se encontra em um lugar no qual as condições para as mulheres são mais difíceis e reconhece que se sente desamparada: “claro, eu sou a vítima perfeita: mulher, sozinha, com aparência de ocidental, logo, estou distante de casa, vulnerável”. Salem (1991), em Entre árabes e judeus, autobiográfico, faz menção ao assédio 
oriundo dos colegas de profissão, que dividiam com ela o mesmo hotel e as coletivas de imprensa no Cairo, em 1973, durante a guerra entre árabes e israelenses.

\title{
6 CONSIDERAÇÕES
}

\begin{abstract}
A crítica [...] pode ser definida como a atitude reflexiva de confronto com o mundo, motivada ou não pela ação dos outros, que nasce da elaboração intelectual do sofrimento que eventualmente sentimos em nós e nos outros e que, pela via da exploração da nossa capacidade de raciocínio e imaginação criadora, procura entender suas origens, características e perspectivas de superação. (RÜDIGER, 2014, p. 122).
\end{abstract}

Os livros Palestina, os novos judeus (1977), de Helena Salem, e Viagem à Palestina: prisão a céu aberto (2013), de Adriana Mabilia, são o resultado de uma escrita reflexiva sobre si e sobre o mundo a partir do embate com o tempo presente, seus temas, acontecimentos e sujeitos. Se retomada a proposição de Rüdiger (2014), a atitude diante do mundo e, principalmente, as elaborações formuladas a partir dela, tanto pelas jornalistas brasileiras quanto pelas fontes por elas apresentadas, constituem-se como crítica. Ainda, segundo o autor, "a reflexão crítica sobre os fenômenos de comunicação constitui em si mesma um fragmento de práxis transformadora" (2010, p. 217).

Os "livros de repórter" constituem-se em ambiência para leituras singularizadas do tempo e do espaço e, especialmente, do próprio Jornalismo. Tal afirmação é resultado do entendimento de que não são os meios de comunicação que definem as práticas jornalísticas, e sim o contrário. Logo, essas práticas, porque afetadas pelas relações sociais, culturais e históricas, insinuam-se também nos livros. Eles se constituem como espaços de exercício da grande reportagem, da reflexão sobre as práticas e o saber jornalísticos e da crítica.

Tomados aqui para análise, os livros de Mabilia (2013) e Salem (1977) revelam modos distintos de crítica das práticas jornalísticas, quais sejam: a crítica tecida pelas jornalistas e endereçada ao Jornalismo, de modo geral, e à cobertura internacional de conflitos, de forma particular; a crítica trazida pelas fontes, e a autocrítica formulada pelas repórteres. Estes modos, por sua vez, são o resultado de um antes, um durante e um depois; foram motivadas pela reflexão interessada acerca:

- Das lógicas empresariais e editoriais dos meios, como a reduzida presença de repórteres no exterior; os escassos investimentos em cobertura; o fato de os conflitos serem narrados preferencialmente a partir de um dos lados; a apuração à distância; a apropriação dos relatos de outros meios e das agências; 
- Da ação de outros jornalistas, como as questões de contexto e o contraste de pontos de vista desaparecem quer na apuração, quer na edição; a ausência de fontes femininas;

- Do próprio fazer, como estar "dentro" e estar "próximo" do que e de quem se narra; falar sobre ou falar com; tratar de questões delicadas para os entrevistados;

- Do estatuto das fontes, como a substituição de fontes que correspondem à autoridade por aquelas capazes de dar relevo aos acontecimentos.

Adriana Mabilia (2013) e Helena Salem (1977) apresentam relatos que não costumamos encontrar nos veículos de comunicação hegemônicos. Apesar de distantes temporalmente, os livros discutem de maneira similar tanto o conflito de que tratam como o Jornalismo. Por meio de uma ação jornalística crítica e responsável, propõem uma mediação do mundo menos fragmentada. E apesar de, assim como os meios que criticam, escolherem um lado, o fazem na contramão da cobertura jornalística internacional tradicional e descrevem o conflito Israel-Palestina e os palestinos a partir deles mesmos.

\section{REFERÊNCIAS}

AGUIAR, Pedro. Jornalismo internacional em redes. Rio de Janeiro: Secretaria Especial de Comunicação Social, 2008. Disponível em:

<http://www.rio.rj.gov.br/dlstatic/10112/4204433/4101411/estudos20.pdf>.

BERGER, Christa; MAROCCO, Beatriz. Fonte. In: MARCONDES FILHO, Ciro. Dicionário da comunicação. 2. ed. rev. e ampl. São Paulo: Paulus, 2014. p. 199-200.

BORRAT, Héctor. El periódico, actor político. Barcelona: Gustavo Gili, 1989.

ESPINOSA DE LOS MONTEROS, Guillermo G. Periodismo Internacional, Corresponsales y Testimonios sobre el Extranjero. Foro Internacional, n. 152-153, México: Hemeroteca Virtual Unam, 1998. p. 415-426. Disponível em:

<http://codex.colmex.mx:8991/exlibris/aleph/a18_1/apache_media/2ABM9V9CHVIEUG92B8Q869C 5KJ7X4I.pdf $>$.

FOUCAULT, Michel. As reportagens de idéias. In: BERGER, Christa; MAROCCO, Beatriz. Ilha do Presídio: uma reportagem de idéias. Porto Alegre: Libretos, 2008. p. 49-51.

HALL, Stuart et al. A produção social das notícias: o mugging nos media. In: TRAQUINA, Nelson (org.). Jornalismo: questões, teorias e "estórias". 2. ed. Lisboa: Vega, 1999.

LAGE, Nilson. A reportagem: teoria e técnica de entrevista e pesquisa jornalística. 8. ed. Rio de Janeiro: Record, 2009.

MABILIA, Adriana. Viagem à Palestina: prisão a céu aberto. Rio de Janeiro: Civilização Brasileira, 2013. 
MAROCCO, Beatriz. Os "livros de repórter", o “comentário" e as práticas jornalísticas. Revista Contracampo, Niterói, n. 22, fev. 2011, p. 116-129. Disponível em:

<http://www.uff.br/contracampo/index.php/revista/article/view/86/67>.

. Reportagem de transgressão, um giro no tratamento da fonte jornalística. In: BERGER, Christa; MAROCCO, Beatriz. Ilha do Presídio: uma reportagem de idéias. Porto Alegre: Libretos, 2008. p. 33-47.

NATALI, João Batista. Jornalismo internacional. 1. ed. 1. reimp. São Paulo: Contexto, 2007.

PERES, Andréa Carolina Schvartz. Notas sobre o jornalismo internacional no Brasil. Observatório da Imprensa, Jornal de Debates, São Paulo, ano 18, n. 844, 22 nov. 2005. Disponível em:

$<$ http://observatoriodaimprensa.com.br/jornal-de-debates/notas-sobre-jornalismo-internacional-nobrasil//>.

RÜDIGER, Francisco. Crítica. In: MARCONDES FILHO, Ciro. Dicionário da comunicação. 2. ed. rev. e ampl. São Paulo: Paulus, 2014. p. 122-123.

. Elementos para a crítica do jornalismo moderno: conhecimento comum e indústria cultural.

Revista Famecos, v. 17, n. 3, p. 216-227, set./dez. 2010. Disponível em:

<http://revistaseletronicas.pucrs.br/ojs/index.php/revistafamecos/article/view/8189>.

SALEM, Helena. Entre árabes e judeus: uma reportagem de vida. São Paulo: Editora Brasiliense, 1991.

. Palestinos, os novos judeus. Rio de Janeiro: Eldorado-Tijuca, 1977.

SANTOS, Rogério. A negociação entre jornalistas e fontes. Coimbra: Minerva, 1997.

SILVA, Carlos Eduardo Lins da. Correspondente internacional. São Paulo: Contexto, 2011.

UTZERI, Fritz. Do outro lado do mundo. In: RITO, Lúcia et al. (orgs.). Imprensa ao vivo. Rio de Janeiro: Rocco, 1989. p. 145-158.

ZAMIN, Angela. Jornalismo de referência: o conceito por trás da expressão. Revista Famecos, v. 21, n. 3, p. 918-942, set.-dez. 2014. Disponível em:

<http://revistaseletronicas.pucrs.br/ojs/index.php/revistafamecos/article/view/16716>.

. Livros de repórter, saberes de entremeio: relatos jornalísticos sobre a cobertura de conflitos.

Estudos em Jornalismo e Mídia, v. 8, p. 389-405, 2011. Disponível em:

<https://periodicos.ufsc.br/index.php/jornalismo/article/view/1984-6924.2011v8n2p389>.

. Nos jornais, um típico acontecimento atípico. O Caso Angostura em diários latinoamericanos de referência. 2012. 277 f. Tese (Doutorado em Ciências da Comunicação) - Unisinos.

Original recebido em: 02/06/2015

Aceito para publicação em: 06/12/2015 
Angela Zamin

Professora do Departamento de Ciências da Comunicação da Universidade Federal de Santa

Maria (UFSM), Campus Frederico Westphalen. Doutora e Mestre em Ciências da Comunicação pela Universidade do Vale do Rio dos Sinos (Unisinos). Coordenadora do Grupo de Pesquisa Resto - Laboratório de Práticas Jornalísticas (CNPq/UFSM).

Taiz Gizele Richter

Graduanda em Jornalismo na Universidade Federal de Santa Maria (UFSM), Campus Frederico Westphalen. Membro do Resto - Laboratório de Práticas Jornalísticas (CNPq/UFSM).

Tatiane Milani

Graduanda em Jornalismo na Universidade Federal de Santa Maria (UFSM), Campus Frederico Westphalen. Membro do Resto - Laboratório de Práticas Jornalísticas (CNPq/UFSM).

Tonie Maria Gregory dos Santos

Bolsista FIPE. Graduanda em Jornalismo na Universidade Federal de Santa Maria (UFSM), Campus Frederico Westphalen. Membro do Resto - Laboratório de Práticas Jornalísticas (CNPq/UFSM).

Esta obra está licenciada sob uma Licença Creative Commons 